\title{
PREVALENSI KELUHAN LOW BACK PAIN (LBP) PADA PETANI DI WILAYAH KERJA UPT KESMAS PAYANGAN GIANYAR APRIL 2015
}

\author{
Kiranjit Kaur
}

Program Studi Pendidikan Dokter, Fakultas Kedokteran Universitas Udavana

\section{ABSTRAK}

Latar Belakang: LBP merupakan gangguan muskuloskeletal yang banyak dikeluhkan oleh petani. Kegiatan yang dilakukan petani umumnya memerlukan posisi tubuh yang statis dan repetitif yang meningkatkan prevalensi keluhan LBP. Selain posisi kerja yang salah, umur, jenis kelamin, lama kerja, masa kerja, posisi kerja, riwayat merokok dan trauma juga merupakan faktor untuk terjadi LBP. Petani di wilayah cakupan kerja UPT payangan berjumlah sebanyak 4.883. Dilihat dari tingginya jumlah petani di wilayah tersebut angka kejadian LBP diperkirakan tinggi. Namun kenyataannya, dari 43.597 total kunjungan pasien ke balai pengobatan tahun 2014, angka kejadian LBP hanya 111.

Tujuan Penelitian: Mengetahui prevalensi keluhan LBP pada petani di wilayah kerja UPT Kesmas Payangan tahun 2015.

Metode Penelitian: Penelitianmenggunakan desain studi deskriptif cross-sectional untuk mengetahui prevalensi keluhan LBPpada petani yang tinggal dan bekerja di wilayah kerja UPT Kesmas Payangan.Populasi dari penelitian ini adalah semua petani yang berada di wilayah kerja UPT Kesmas Payangan. Pengumpulan data dilakukan dengan wawancara terstruktur menggunakan kuesioner lalu dilakukan analisis secara univariat dan bivariat.

Hasil:Sebanyak 68,6\% (48 orang) responden mengeluh LBP. Perempuan (71\%)lebih banyak mengalami LBP dibandingkan dengan laki-laki $(66,7 \%)$. Kelompok usia dengan keluhan $>45$ tahun paling banyak mengalami LBP $(73,3 \%)$. Sebanyak $63,6 \%$ petani yang memiliki waktu kerja kurang dari 5 jam dan sebanyak 70,6\% petani yang bekerja lebih dari 5 jam mengalami LBP. Sebanyak 60\% petani yang bekerja kurang dari 10 tahun mengalami LBP dan sebanyak $69,2 \%$ petani yang bekerja lebih dari 10 tahun mengalami LBP. Sebanyak 72,7\% petani yang merokok mengalami LBP dan sebanyak $64,9 \%$ petani yang tidak merokok mengalami LBP. Keluhan LBP terbanyak dikeluhkan oleh petani yang sering melakukan posisi kerja membungkuk (68,6\%). Sebanyak $93,75 \%$ petani yang tidak memiliki riwayat jatuh mengalami LBP. Perilaku tatalaksanan keluhan LBP yang dilakukan terbanyak adalah pemijatan $(27,1 \%)$. Sebanyak $91,7 \%$ petani mengalami minimal disability dan sebanyak $8,3 \%$ petani mengalami moderate disability.

Kesimpulan: Prevalensi LBP tertinggi ditemukan pada perempuan, dengan kelompok usia $>45$ tahun, lama kerja $\geq 5$ jam, masa kerja $\geq 10$ tahun, memiliki riwayat merokok, sering melakukan posisi bungkuk, tidak memiliki riwayat trauma, perilaku tatalaksana keluhan dengan pemijatan dan mengalami minimal disability.

Kata kunci: low back pain, petani, desa payangan

\section{PENDAHULUAN}

Low back pain (LBP) atau nyeri punggung bawah merupakan gangguan muskuloskeletal yang dapat disebabkan oleh berbagai penyakit muskuloskeletal, gangguan psikologis, dan mobilisasi yang salah. LBP berdasarkan definisinya adalah nyeri punggung bawah yang berasal dari tulang belakang, otot, saraf atau struktur lain pada daerah tersebut (Rakel D, 2011).

Low back pain adalah salah satu keluhan yang dirasakan oleh sebagian besar pekerja, umumnya mulai dirasakan pada usia 25 tahun dan meningkat pada usia 50 tahun (Yunus M, 2008). Penelitian dari kelompok studi nyeri Perhimpunan Dokter 
Saraf Indonesia (PERDOSSI) menemukan bahwa jumlah penderita LBP sebanyak 35,86 persen dari total kunjungan pasien nyeri (PERDOSSI, 2007). Enam puluh lima koma lima persen dari penderita LBP adalah wanita, dan persentase penderita tertinggi pada rentang umur 41 hingga 60 tahun (Purba JS, 2006).

Berdasarkan penelitian di Indonesia, prevalensi penderita penyakit muskuloskeletal tertinggi menurut pekerjaan adalah petani (Badan Penelitian dan Pengembangan Kesehatan, 2013). Data dari survei work-related disease menunjukkan bahwa dari 43.000 pekerja di sektor pertanian, 27.000 pekerja mengalami keluhan LBP (Gusetoiu R, 2011). Banyak faktor resiko yang berhubungan dengan keluhan LBP, seperti hereditas, usia, jenis kelamin, deformitas postur tubuh, aktivitas fisik, masa kerja, dan porsi kerja (Silviyani V, 2014). Faktor lainnya adalah faktor fisik yang mencakup ketegangan fisik, seringnya mengangkat beban, dan postur kerja yang kurang tepat (Andini F, 2015). Terdapat pula hubungan antara perilaku merokok dengan nyeri pinggang, dimana ditemukan perokok lebih banyak yang menderita LBP dibandingkan yang tidak pernah merokok sama sekali (Silviyani V, 2014).

Anamnesis yang akurat dan pemeriksaan fisik sangatlah diperlukan dalam mengevaluasi nyeri punggung bawah. Pada umumnya, pasien terbangun dengan nyeri di pagi hari ataupun nyeri tersebut muncul setelah melakukan beberapa gerakan seperti membungkuk, berputar, atau mengangkat barang. Nyeri yang muncul dari struktur tulang belakang dapat menjalar hingga tungkai bawah, namun pada umumnya tidak melebihi lutut (Andini F, 2015).

Pemeriksaan radiologi tidak dianjurkan untuk dilakukan pada seluruh pasien dengan keluhan LBP, pemeriksaan ini hanya dianjurkan pada pasien dengan tanda dan gejala yang mengindikasikan adanya penyakit dasar yang serius seperti kanker, sindroma cauda equina, fraktur dan infeksi (Andini $F, 2015)$.

LBP pada umumnya tidak mengakibatkan kecacatan, namun pada pekerja dapat menurunkan tingkat produktivitas kerja, menurunkan performa kerja, serta kualitas kerja, konsentrasi kerja dan juga secara tidak langsung meningkatkan resiko terjadinya kecelakaan (Gusetoiu R, 2011). Sebuah penelitian memaparkan bahwa 11 persen tenaga kerja dengan LBP mengalami gangguan aktivitas kerja hingga 4 minggu. Lebih dari 50 persen penderita membaik dalam waktu satu minggu, dan lima persen penderita mengalami gangguan aktivitas hingga lebih dari enam bulan.(Andini F, 2015).

Jumlah penduduk di wilayah cakupan kerja dari UPT Kesmas Payangan berkisar 43.216 jiwa, dimana 4.883 jiwa bermata pencaharian sebagai petani (Badan Pusat Statistik Kabupaten Gianyar, 2013). Tingginya jumlah petani di daerah ini menjadi pertimbangan akan tingginya kejadian LBP. Pada kenyataannya kunjungan pasien dengan keluhan LBP di balai pengobatan UPT Kesmas pada tahun 2014 hanya berkisar 111 dari 43.597 total jumlah kunjungan. Berdasarkan survei pada sepuluh orang petani, 9 dari mereka mengeluh pernah mengalami nyeri punggung bawah namun mereka tidak mencari pengobatan ke Puskesmas maupun penyedia pelayanan kesehatan lainnya. Hal tersebut menjelaskan minimnya kunjungan pasien LBP di balai pengobatan UPT Kesmas Payangan.

Berlandaskan hal-hal di atas, dilakukan penelitian yang bertujuan untuk mengetahui karakteristik sebaran LBP pada petani khususnya yang bekerja di cakupan wilayah UPT Kesmas Payangan. Penelitian ini diharapkan dapat memberikan informasi bagi setiap kalangan mengenai distribusi keluhan LBP dan gambaran faktor resiko yang berkaitan dengan LBP pada petani agar dikemudian hari dapat ditentukan langkah-langkah pencegahan dan penanganan untuk menurunkan jumlah kejadian LBP pada petani.

\section{BAHAN DAN METODE}

Penelitian ini menggunakan desain studi deskriptif cross-sectional untuk mengetahui prevalensi keluhan low back pain pada petani yang tinggal dan bekerja di wilayah kerja UPT Kesmas Payangan. Data yang digunakan dalam penelitian ini berupa data primer yang diperoleh dari hasil wawancara berdasarkan pertanyaan kuesioner yang diberikan kepada petani yang tinggal dan bekerja di wilayah kerja UPT Kesmas Payangan. 
Populasi dari penelitian ini adalah petani yang berada di wilayah kerja UPT Kesmas Payangan Bulan Aprl 2015 . Sampel penelitian ini adalah semua petani yang tinggal dan bekerja di wilayah kerja UPT Kesmas Payangan Bulan April 2015. Teknik pengambilan sampel menggunakan metode snowball sampling. Sampel awal diambil dari register pasien LBP di Balai Pengobatan UPT Kesmas Payangan yang tinggal dan bekerja di wilayah cakupan kerja UPT Kesmas Payangan. Sampel awal diminta untuk menunjuk petani lain yang bekerja dan tinggal di wilayah cakupan kerja UPT Kesmas Payangan, begitu seterusnya sampai tercapai sampel yang diinginkan yaitu 70 sampel. Pengumpulan data dilakukan dengan wawancara terstruktur menggunakan kuesioner kepada petani yang tinggal dan bekerja di wilayah kerja UPT Kesmas Payangan. Sebelum wawancara berdasarkan pertanyaan kuesioner, responden dimintai persetujuan terlebih dahulu dengan membubuhkan tanda tangan atau cap jempol pada lembar kuesioner yang diberikan. Data diperoleh melaui wawancara berdasarkan pertanyaan kuesioner tanpa mencantumkan nama responden. Sebelum melakukan analisis data, dilakukan data entry yang sebelumnya telah melalui tahap coding dan editing, kemudian dilanjutkan dengan data cleaning yang dilakukan terhadap semua variabel untuk mengetahui data yang tidak sesuai (missing) sehingga akan diperoleh data yang baik untuk dianalisis. Analisis data dilakukan dengan menggunakan perangkat lunak komputer. Adapun analisis yang dilakukan berupa analisis univariat dan bivariat. Analisis univariat merupakan analisis yang dilakukan terhadap tiap variabel dalam hasil penelitian. Pada analisis ini akan didapatkan distribusi frekuensi dan persentase dari masingmasing variabel meliputi keluhan LBP, jenis kelamin, umur, lama kerja, masa kerja, riwayat trauma, perilaku tatalaksana LBP pada petani dan tingkat disabilitas fungsional. Analisis bivariat berupa tabulasi silang (cross-tab) dimana dalam penelitian ini dilakukan tabulasi silang antara variabel umur, jenis kelamin, lama kerja, masa kerja, riwayat merokok, posisi kerja, dengan keluhan LBP.

\section{HASIL PENELITIAN

Karakteristik Responden Berdasarkan
Sosiodemografi

Dari 70 sampel yang ikut dalam penelitian ini, diperoleh usia responden yang ikut dalam penelitian ini mulai dari usia 25 tahun hingga 70 tahun. Kelompok usia responden dibagi menjadi dewasa muda (< 35 tahun), dewasa (35-44 tahun) dan lansia (>45 tahun). Kelompok usia terbanyak dalam penelitian ini adalah kelompok usia > 45 tahun yang berjumlah 30 orang (42,9\%), sedangkan untuk kelompok umur < 35 tahun berjumlah 14 orang $(20,0 \%)$, kelompok usia 35-44 tahun berjumlah 26 orang $(37,1 \%)$. Jenis kelamin sampel yang terbanyak adalah laki-laki dengan jumlah responden 39 orang (54,9\%) dan perempuan sebanyak 31 orang $(44,3 \%)$. Secara lengkap distribusi frekuensi karakteristik berdasarkan sosiodemografi pada table 1 .

Tabel 1. Karakteristik Responden Berdasarkan Sosiodemografi

\begin{tabular}{cc}
\hline & $\begin{array}{l}\text { Frekuensi } \\
\text { (persentase \%) }\end{array}$ \\
\hline Umur & $14(20,0)$ \\
$<\mathbf{3 5}$ tahun & $26(37,1)$ \\
$\mathbf{3 5 - 4 4}$ tahun & $30(42,9)$ \\
$>$ 45 tahun & \\
\hline Jenis Kelamin & $39(55,7)$ \\
Laki-laki & $31(43,3)$ \\
\hline
\end{tabular}

Tabel 2. Karakteristik Responden Berdasarkan Faktor Risiko

\begin{tabular}{cc}
\hline Karakteristik & $\begin{array}{l}\text { Frekuensi } \\
\text { (persentase \%) }\end{array}$ \\
\hline $\begin{array}{c}\text { Lama Kerja } \\
<5 \text { jam }\end{array}$ & $22(31,4)$ \\
$\geq 5$ jam & $48(68.6)$ \\
\hline $\begin{array}{c}\text { Masa Kerja } \\
<10 \text { Tahun }\end{array}$ \\
$\geq 10$ Tahun & $5(7,1)$ \\
Ya & $65(92,9)$ \\
Tidak & $3(4,3)$ \\
Ya Merokok & $67(95,7)$ \\
\hline Frekuensi (hari) & $33(47,1)$ \\
\hline
\end{tabular}




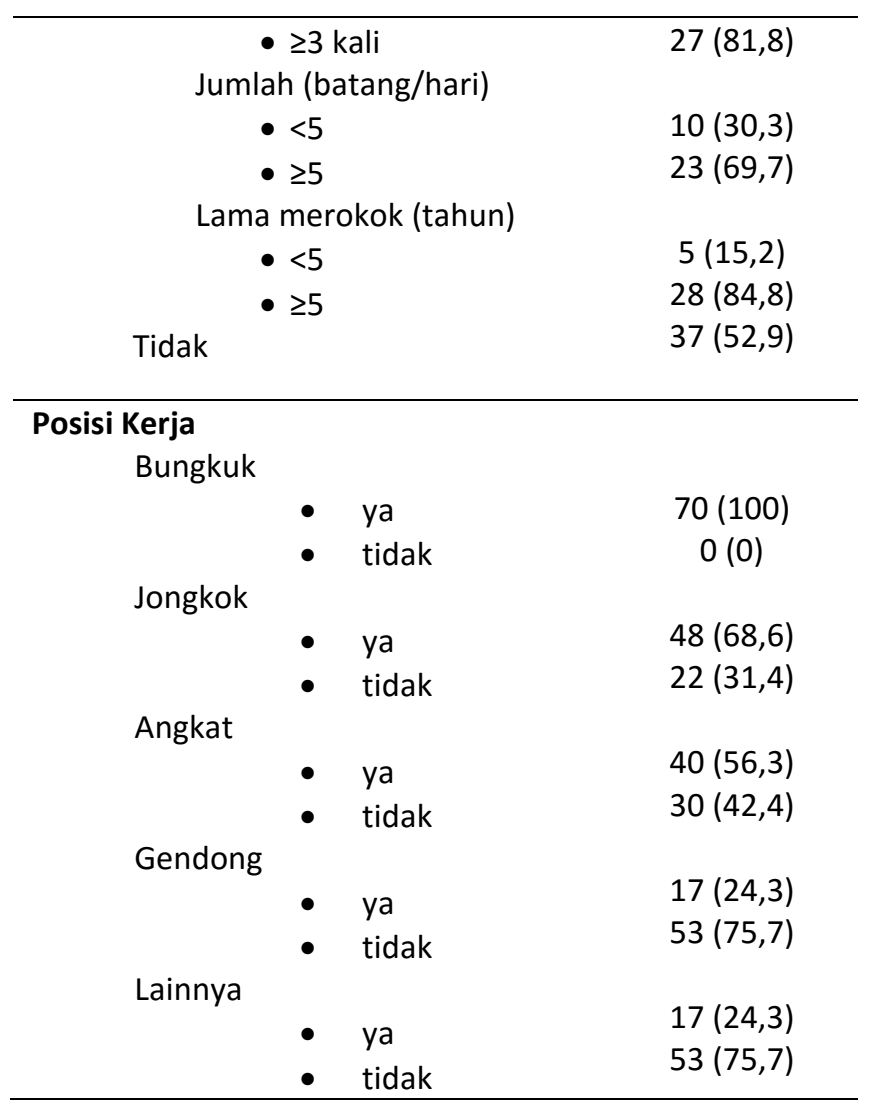

\section{Karakteristik Responden berdasarkan Faktor Risiko}

Dari hasil penelitian kepada petani menurut lama kerja, diperoleh sampel yang bekerja kurang dari 5 jam sehari berjumlah 22 orang $(31,4 \%)$ dan yang bekerja lebih sama dengan 5 jam sehari berjumlah 65 orang $(68,6 \%)$. Untuk masa kerja, sampel yang bekerja kurang dari 10 tahun sebagai petani berjumlah 5 orang $(7,1 \%)$ dan yang sudah bekerja lebih dari sama dengan 10 tahun berjumlah 65 orang (92,9\%). Petani yang tidak memiliki riwayat merokok berjumlah sebanyak 44 orang $(62,9 \%)$ dan yang memiliki riwayat merokok berjumlah 26 orang $(37,1 \%)$. Dari responden yang memiliki riwayat merokok, diperoleh petani yang memiliki frekuensi merokok kurang 3 kali sebanyak 6 orang $(23,1 \%)$ dan yang memiliki frekuensi lebih dari sama dengan 3 kali sebanyak 20 Orang (76,9\%). Petani yang merokok kurang 5 batang/hari berjumlah sebanyak 11 orang $(42,3 \%)$ dan petani yang merokok lebih dari lebih dari sama dengan 5 batang/hari berjumlah 15 orang $(57,7 \%)$. Petani yang merokok kurang dari 5 tahun berjumlah 8 orang $(30,8 \%)$ dan yang merokok lebih dari sama dengan 5 tahun berjumlah 18 orang (69,2\%). Sampel yang memiliki LBP setelah mengalami riwayat trauma berjumlah 3 orang $(4,3 \%)$ dan yang tidak memiliki riwayat trauma bejumlah 67 orang $(95,7 \%)$. Petani yang sering bekerja dengan posisi bungkuk berjumlah 70 orang (100\%), yang sering melakukan posisi jongkok berjumlah 48 orang $(68,6 \%)$, yang sering melakukan posisi angkat berjumlah 40 orang $(56,3 \%)$ dan yang sering melakukan posisi lainnya seperti mendorong, membajak sawah berjumlah 17 orang $(24,3 \%)$.

\section{Prevalensi Keluhan LBP pada petani di Wilayah Kerja UPT Kesmas Payangan}

Berdasarkah hasil penelitian, diperoleh jumlah petani yang memiliki keluhan LBP sebanyak $68,6 \%$ (48 orang) dan sebanyak 31,4\% (22 orang) tidak memiliki keluhan LBP selama satu bulan terakhir.

Tabel 3. Prevalensi Keluhan LBP pada Petani.

\begin{tabular}{cc}
\hline Keluhan LBP & Frekuensi (Persentase \%) \\
\hline Ya & $48(68,6)$ \\
Tidak & $22(31,4)$ \\
Jumlah & $70(100)$
\end{tabular}

Tabel 4. Prevalensi Keluhan LBP pada Petani Berdasarkan Sosiodemografi.

\begin{tabular}{ccccccc} 
& & \multicolumn{5}{c}{ LBP } \\
\cline { 3 - 6 } & & \multicolumn{3}{c}{ Ya } & \multicolumn{2}{c}{ Tidak } \\
& & Jumlah & (\%) & Jumlah & (\%) & Jumlah \\
\hline Jenis & Laki-laki & 26 & 66,7 & 13 & 33,3 & 39 \\
Kelamin & Perempuan & 22 & 71,0 & 9 & 29 & 31 \\
Usia & $<35$ & 8 & 57,1 & 6 & 42,9 & 14 \\
(Tahun) & $35-44$ & 18 & 69,2 & 8 & 30,8 & 26 \\
\hline
\end{tabular}




8

26,7 30

Tabel 5. Prevalensi Keluhan LBP pada Petani Menurut Faktor Risiko Lama Kerja dan Masa Kerja, Riwayat Merokok, dan Posisi Kerja.

\begin{tabular}{|c|c|c|c|c|c|c|}
\hline & & \multicolumn{4}{|c|}{ LBP } & \multirow[b]{3}{*}{ Jumlah } \\
\hline & & \multicolumn{2}{|c|}{$\mathrm{Ya}$} & \multicolumn{2}{|c|}{ Tidak } & \\
\hline & & Jumlah & (\%) & Jumlah & (\%) & \\
\hline Lama Kerja & $<5$ & 14 & 63,6 & 8 & 36,4 & 22 \\
\hline (jam) & $\geq 5$ & 34 & 70,6 & 14 & 29,3 & 48 \\
\hline \multirow{2}{*}{$\begin{array}{l}\text { Masa Kerja } \\
\text { (tahun) }\end{array}$} & $<10$ & 3 & 60,0 & 2 & 40,0 & 5 \\
\hline & $\geq 10$ & 45 & 69,2 & 20 & 30,8 & 65 \\
\hline Riwayat & $\mathrm{Ya}$ & 24 & 72,7 & 9 & 27,3 & 33 \\
\hline \multirow[t]{9}{*}{ Merokok } & - Frekuensi (hari) & & & & & \\
\hline & - $<3$ kali & 4 & 66,7 & 2 & 33,3 & 6 \\
\hline & - $\geq 3$ kali & 23 & 85,2 & 4 & 14,8 & 27 \\
\hline & - Jumlah & & & & & \\
\hline & - $<5$ batang & 9 & 90,0 & 1 & 10,0 & 10 \\
\hline & - $\geq 5$ batang & 19 & 82,6 & 4 & 17,4 & 23 \\
\hline & - Lama Merokok & 4 & 80,0 & 1 & 20,0 & 5 \\
\hline & - $\geq 5$ tahun & 25 & 89,3 & 3 & 10,7 & 28 \\
\hline & Tidak & 24 & 64,9 & 13 & 13 & 37 \\
\hline \multirow[t]{5}{*}{ Posisi Kerja } & Bungkuk & 48 & 68,6 & 22 & 31,4 & 33 \\
\hline & Jongkok & 21 & 63,6 & 12 & 36,4 & 33 \\
\hline & Angkat & 27 & 67,5 & 13 & 32,5 & 40 \\
\hline & Gendong & 10 & 58,8 & 7 & 41,2 & 17 \\
\hline & Lainnya & 13 & 76,5 & 4 & 23,5 & 17 \\
\hline
\end{tabular}

\section{Prevalensi Keluhan LBP pada Petani Berdasarkan} Sosiodemografi

Pada penelitian ini dilakukan uji bivariat mengenai keluhan LBP dan sosiodemografi. Diperoleh hasil penelitian, bahwa petani yang mengalami LBP didominasi oleh perempuan (71\%) sedangkan laki-laki yang mengeluh LBP sebesar $66,7 \%$. Bila ditinjau dari segi usia, didapatkan bahwa kejadian LBP tertinggi yaitu pada kelompok usia > 45 tahun dengan persentase $73,3 \%$ dan terendah adalah pada kelompok usia $<35$ tahun dengan persentase $57,1 \%$.

\section{Prevalensi Keluhan LBP pada Petani Menurut Faktor Risiko}

Pada penelitian ini dilakukan uji bivariat mengenai keluhan LBP dengan lama kerja, masa kerja, posisi kerja dan riwayat merokok. Diperoleh hasil penelitian, dari 70 oranh responden, ditemukan sebanyak $63,6 \%$ petani yang bekerja kurang dari 5 jam dalam sehari mengeluh LBP dan sebanyak 70,6\% petani yang bekerja lebih dari 5 jam sehari mengeluh LBP. Bila dilihat dari masa kerja, sebanyak $60 \%$ petani yang bekerja kurang dari 10 tahun mengeluh mengalami LBP, sedangkan $69,2 \%$ petani yang bekerja lebih dari 10 tahun mengeluh LBP. Berdasarkan hasil penelitian mengenai posisi kerja, diperoleh bahwa petani yang lebih sering melakukan posisi membungkuk lebih banyak mengalami keluhan LBP $(68,6 \%)$ dibandingkan dengan posisi tubuh lain seperti jongkok $(63,6 \%)$, angkat $(67,5 \%)$, gendong $(58,8 \%)$ dan posisi lainnya seperti menggunakan traktor. Berdasarkan riwayat merokok, ditemukan sebanyak $72,7 \%$ petani yang merokok mengeluh LBP sedangkan sebanyak $64,9 \%$ petani yang tidak merokok mengalami LBP. Dari petani yang merokok dan mengeluh LBP, diperoleh petani yang 
merokok dengan frekuensi $<3$ kali sehari berjumlah sebanyak $66,7 \%$ sedangkan yang batang sehari sebanyak $90 \%$ dan $\geq 5$ batang sehari sebanyak $82,6 \%$ dan petani yang merokok $<5$ tahun sebanyak $80 \%$ dan yang merokok $\geq 5$ tahun sebanyak $89,3 \%$. Dari 48 petani yang mengeluh LBP, sebanyak $4,17 \%$ memiliki riwayat jatuh yang menimbulkan keluhan LBP, sedangkan 2,08\% lainnya memiliki riwayat kecelakaan. Sisanya $(93,75 \%)$ tidak memiliki riwayat trauma yang menyebabkan terjadinya keluhan LBP.

Tabel 6. Prevalensi Riwayat Trauma pada

Responden dengan Keluhan LBP.

\begin{tabular}{cl}
\hline Riwayat Trauma & $\begin{array}{l}\text { Frekuensi } \\
\text { (Persentase \%) }\end{array}$ \\
\hline Jatuh & $2(4,17)$ \\
Kecelakaan & $1(2,08)$ \\
Lainnya & $0(0,0)$ \\
Tidak ada & $45(93,75)$ \\
Jumlah & $48(100)$ \\
\hline
\end{tabular}

Perilaku Tatalaksana LBP pada Petani

Dari perilaku petani dalam mencari penatalaksanaan untuk keluhan LBP, diperoleh pemijatan $(27,1 \%)$ merupakan usaha terbanyak petani dalam mengatasi keluhan LBP, diikuti oleh berobat pada petugas kesehatan (22,9\%), didiamkan $(20,8)$, diolesi salep atau minyat urut $(18,8 \%)$ dan pengobatan lainnya $(10,4 \%)$ seperti pengobatan tradisional dengan menggunakan jamu.

Tabel 7. Perilaku Tatalaksana Keluhan LBP pada Petani.

\begin{tabular}{ll}
\hline Penatalaksanaan & $\begin{array}{l}\text { Frekuensi } \\
\text { (Persentase \%) }\end{array}$ \\
\hline Didiamkan & $10(20,8)$ \\
Oles & $9(18,8)$ \\
Pijat & $13(27,1)$ \\
Berobat Yankes & $11(22,9)$ \\
Lainnya & $5(10,4)$ \\
\hline
\end{tabular}

\section{Tingkat Disabilitas Fungsional pada Petani dengan Keluhan LBP}

Setelah diwawancara terstruktur menggunakan kuisioner Oswestry low back pain disability. tingkat disabilitas fungsional pada petani dengan keluhan LBP, diperoleh sebanyak 91,7\% (44 orang) petani mengalami minimal disability merokok dengan frekuensi $\geq 3$ kali berjumlah $85,2 \%$, petani yang merokok dengan jumlah $<5$ dan sebanyak 8,3\% (4 orang) mengalami moderate disability.

\section{PEMBAHASAN}

Prevalensi Keluhan LBP pada petani di Wilayah Kerja UPT Kesmas Payangan

Ditinjau dari prevalensi keluhan LBP pada petani yang dilakukan pada 70 orang sampel, didapatkan sebanyak 68,6\% petani mengeluh mengalami LBP. Hal ini diperkuat oleh penelitian yang dilakukan oleh Gupta (2013) kepada petani di Kanpur India tahun 2013 ditemukan keluhan musculoskeletal terbanyak yang dialami petani adalah LBP, yaitu sebanyak $60 \%$. Penelitian lain yang dilakukan oleh Panada (2011) juga menyatakan prevalensi keluhan LBP pada petani beras di Thailand sebanyak 77,4\%. Birabi BN (2012), yang juga melakukan penelitian pada petani di wilayah Selatan Nigeria, menemukan sebanyak 67,10\% petani memiliki keluhan LBP. Petani banyak mengalami LBP dikarenakan saat bekerja mereka melakukan gerakan yang berisiko seperti membungkuk, gerakan memutar badan dan paparan lainnya akibat getaran traktor dan membawa beban berat yang akan mempengaruhi spinal disc dan menyebaban kerusakan pada baik secara mekanik maupun biologis. Pekerjaan petani juga memerlukan posisi yang statis dan repetitif yang menyebabkan risiko lebih besar untuk terjadinya LBP. Dilihat dari prevalensi LBP yang tinggi pada petani di Wilayah Kerja UPT Kesmas Payangan, maka pencegahan sebaiknya dilakukan. Pencegahan dapat diberikan melalui edukasi melalui penyuluhan mengenai posisi kerja yang ergonomis pada petani sehingga angka kejadian LBP dan morbiditasnya dapat menurun.

\section{Prevalensi Keluhan LBP pada Petani Berdasarkan Sosiodemografi}

Berdasarkan keluhan LBP menurut jenis kelamin, ditemukan bahwa prevalensi keluhan LBP lebih banyak terjadi pada perempuan (71,0\%) dibandingkan pada laki-laki (66,7\%). Hal ini sesuai dengan penelitian yang dilakukan NIOSH (1997) yang meneliti mengenai pekerja yang mengalami keluhan muskulosekeltal, ditemukan prevalensi 
beberapa kasus musculoskeletal disorders lebih tinggi terjadi pada perempuan dibandingkan pada laki-laki. Peneliti lain, Birabi BN (2012), juga menyebutkan keluhan LBP lebih banyak terjadi pada perempuan yaitu sebanyak 50.96\%. Perempuan lebih banyak mengalami LBP dibandingkan laki-laki karena perempuan memiliki pekerjaan sampingan seperti melakukan pekerjaan rumah disamping bekerja sebagai petani. Hal ini meningkatkan Risiko untuk terjadinya LBP. Selain itu, menurut Velina, dkk (2013) tingkat kemampuan otot perempuan secara fisiologis lebih rendah bila dibandingkan dengan laki-laki. Perempuan hanya memiliki kekuatan otot $60 \%$ dari kekuatan otot laki-laki, terutama untuk otot lengan, punggung dan kaki. Masa otot yang lebih kecil menyebabkan meningkatnya prevalensi keluhan LBP pada wanita.

Bila ditinjau dari segi usia, didapatkan bahwa kejadian LBP tertinggi yaitu pada kelompok usia > 45 tahun dengan persentase 73,3\%. Menurut penelitian yang dilakukan oleh Garg dalam Pratiwi (2009) yang menyatakan insiden LBP tertinggi pada kelompok usia 35-55 tahun. Andini (2015) dalam tulisannya berjudul Risk Factor Of Low Back Pain In Workers menyatakan keluhan LBP mulai terjadi pada usia 35 tahun dan akan semakin meningkat pada usia 55 tahun. Hal ini disebabkan karena pertambahan umur seseorang tidak disertai dengan peningkatan kapasitas fisik dan kemampuan fungsional. Salah satu akibat dari proses degeneratif adalah terjadinya proses degenerasi pada tulang sehingga meningkatkan Risiko LBP. Hal ini sering terjadi pada usia pekerja diatas 40 tahun. Menurut Atmantika (2014), proses terjadinya LBP banyak terjadi pada usia 4050 tahun. Hal ini karena dalam rentang umur tersebut terjadi degenerasi diskus intervetrebralis.

\section{Prevalensi Keluhan LBP pada Petani Menurut Faktor Risiko Lama Kerja \\ Berdasarkan hasil penelitian dari segi lama petani menghabiskan waktu bekerja di sawah, petani yang memiliki jam kerja diatas 5 jam memiliki keluhan LBP lebih banyak (70,6\%) dibandingkan dengan petani yang memiliki jam kerja kurang dari 5 jam sehari (63,6\%). Hal ini sesuai dengan penelitian yang dilakukan Kantana (2010) yang}

meneliti keluhan LBP pada kegiatan mengemudi tim ekspedisi, yang menyebutkan semakin lama waktu bekerja atau semakin lama seseorang terpajan faktor Risiko, maka semakin besar pula risiko untuk mengalami LBP. Ini disebabkan karena semakin lama waktu bekerja petani, maka petani akan berada pada posisi tubuh statis dan tidak ergonomis dalam jangka waktu yang lama sehingga akan menyebabkan terjadinya kelelahan otot yang dapat meningkatkan Risiko terjadinya musculoskeletal disorders.

\section{Prevalensi Keluhan LBP pada Petani Menurut Faktor Risiko Masa Kerja}

Bila ditinjau dari masa kerja petani, petani yang bekerja lebih sama dengan 10 tahun lebih banyak yang mengalami LBP $(69,2 \%)$ dibandingkan dengan petani yang bekerja kurang dari 10 tahun (60,0\%). Hal ini diperkuat dengan hasil penelitian yang dilakukan Umami (2013) yang menyebutkan bahwa pekerja yang memiliki keluhan LBP paling banyak dirasakan oleh pekerja yang memiliki masa kerja >10 tahun dibandingkan dengan mereka dengan masa kerja $<5$ tahun ataupun 5-10) tahun. Dimana LBP sebagai penyakit kronis yang membutuhkan waktu lama untuk menimbulkan gejala. Jadi semakin lama waktu bekerja atau semakin lama pekerja terkena faktor Risiko maka semakin besar timbulnya Risiko untuk mengalami LBP.

\section{Prevalensi Keluhan LBP pada Petani Menurut Faktor Risiko Riwayat Merokok}

Berdasarkan hasil penelitian menurut riwayat merokok, petani yang merokok (72,7\%) lebih banyak mengalami LBP dibandingkan dengan petani yang tidak merokok 64,9\%. Hal ini sesuai dengan penelitian yang dilakukan oleh Tana L (2011) yang menyebutkan dalam penelitiannya bahwa responden yang memiliki riwayat merokok lebih banyak menderita LBP dibandingkan dengan yang tidak merokok sama sekali. Merokok dikatakan memiliki hubungan yang signifikan antara kebiasaan merokok dengan keluhan otot pinggang, khususnya untuk pekerjaan yang memerlukan pengerahan otot, $\mathrm{Hal}$ ini disebabkan karena nikotin yang terdapat pada rokok dapat 
menyebabkan berkurangnya aliran darah ke jaringan. Selain itu, merokok dapat pula menyebabkan berkurangnya kandungan mineral pada tulang sehingga menyebabkan nyeri akibat terjadinya keretakan atau kerusakan pada tulang.

Dari hasil penelitian sebelumnya tidak ditemukan jumlah pasti mengenai berapa frekuensi, jumlah batang dan lama pasien merokok. Namun pada penelitan ini diperoleh petani yang merokok dengan frekuensi <3 kali sehari berjumlah sebanyak $66,7 \%$ sedangkan yang merokok dengan frekuensi $\geq 3$ kali berjumlah $85,2 \%$, petani yang merokok dengan jumlah $<5$ batang sehari sebanyak $90 \%$ dan $\geq 5$ batang sehari sebanyak $82,6 \%$ dan petani yang merokok <5 tahun sebanyak $80 \%$ dan yang merokok $\geq 5$ tahun sebanyak $89,3 \%$.

\section{Prevalensi Keluhan LBP pada Petani Menurut Faktor Risiko Posisi Kerja}

Berdasarkan hasil penelitian mengenai posisi kerja, diperoleh bahwa petani yang sering melakukan posisi kerja "bungkuk" lebih banyak mengalami keluhan LBP $(68,6 \%)$ dibandingkan dengan posisi tubuh lain seperti jongkok (63,6\%), angkat $(67,5 \%)$, gendong $(58,8 \%)$ dan posisi lainnya. Posisi tubuh yang tidak ergonomis saat bekerja akan menyebabkan munculnya MSDs dimana LBP merupakan salah satu MSDs yang banyak dikeluhkan oleh petani. Menurut penelitian Velina, dkk (2013) dalam Hubungan posisi bekerja petani Lansia dengan Risiko Terjadinya Nyeri Punggung Bawah Di Wilayah Kerja Puskesmas Sumber Jambe Kabupaten Jember, sebanyak 56,8\% petani melakukan posisi kerja membungkuk yang tidak ergonomis yang menyebabkan timbulnya keluhan LBP. Posisi kerja membungkuk yang dilakukan secara statis dan repetitif akan mempengaruhi spinal disc dan menyebaban kerusakan pada baik secara mekanik maupun biologis sehingga akan muncul LBP. Sikap yang tidak baik dalam bekerja mengakibatkan tubuh menjadi cepat lelah dan menimbulkan ketegangan otot sehingga menyebabkan timbul nyeri.

\section{Prevalensi Keluhan LBP pada Petani Menurut Faktor Risiko Riwayat Trauma}

Berdasarkan hasil wawancara mengenai riwayat trauma yang berkaitan dengan keluhan LBP, sebanyak $4,17 \%$ responden memiliki riwayat jatuh dan $2,08 \%$ memiliki riwayat kecelakaan. Sembilan puluh tiga koma tujuh puluh lima persen responden mengaku tidak memiliki riwayat trauma yang berkaitan dengan LBP. Berdasarkan penelitian yang dilakukan oleh Andini (2011), riwayat terjadinya trauma pada tulang belakang merupakan faktor Risiko terjadinya LBP karena trauma akan merusak struktur tulang belakang yang dapat mengakibatkan nyeri yang terus menerus.

\section{Perilaku Tatalaksana LBP pada Petani}

Berdasarkan hasil penelitian menurut perilaku petani dalam mencari pertolongan untuk keluhan LBP, diperoleh pemijatan (27,1\%) merupakan usaha terbanyak petani dalam mengatasi keluhan LBP, diikuti oleh berobat pada petugas keseatan $(22,9 \%)$, didiamkan $(20,8)$, diolesi salep atau minyat urut $(18,8 \%)$ dan pengobatan lainnya $(10,4 \%)$. Hasil tersebut memiliki gambaran yang sama dengan penelitian terdahulu yang dilakukan oleh Chiwaridzo (2013) dimana sebagian besar penderita LBP tidak mencari pengobatan ke tenaga medis. Menurut penelitian yang dilakukan Lamsudin (2001), 90\% LBP akut dapat membaik dalam 6 minggu, hal tersebut menjadi salah satu pertimbangan dari para responden untuk tidak mengunjungi layanan kesehatan karena dirasa keluhannya membaik dalam hitungan hari.

Di UPT Kesmas Payangan sendiri memiliki tenaga kesehatan dalam bidang fisioterapi. Namun tenaga fisioterapi dialokasikan pada program lain karena pihak UPT Kesmas Payanga tidak memiliki poliklinik fisoterapi. Padahal penelitian yang dilakukan Priyambodo (2008) tentang Penatalaksanaan Fisioterapi pada Kondisi Low Back Pain Miogenik di RSUD Boyolali menyatakan setelah melakukan 6 kali terapi fisioterapi pada pasien dengan LBP, diperoleh pengurangan rasa nyeri baik nyeri tekan, nyeri diam dan nyeri gerak.

\section{Prevalensi Keluhan LBP pada Petani Menurut Tingkat Disabilitas Fungsional \\ Berdasarkan hasil penelitian menurut dampak LBP pada kehidupan sehari-hari, dari 48 petani yang mengalami LBP, sebanyak 91,7\% petani mengalami}


minimal disability dan sisanya (8,3\%) mengalami moderate disability. Menurut penelitian yang dilakukan Atmantika (2014) dalam penelitiannya yang berjudul Hubungan antara Intensitas Nyeri dengan Keterbatasan Fungsional Aktivitas Seharihari pada Penderita LBP di RSUD dr. Moewardi di Surakataka menyatakan nyeri dapat menyebabkan terjadinya gangguan dan keterbatasan fungsional. Dimana gangguan pada tubuh ini disebabkan karena menurunnya fungsi anatomi, fisiologi dan psikologis. Keterbatasan fungsional akibat dampak nyeri akan menyebabkan seseorang mengalami keterbatasan dalam beraktivitas. Semakin berat nyeri yang dirasakan, maka semakin berat keterbatasan yang dialaminya. Semakin ringan nyeri yang dirasakan, maka penderita masih mampu untuk menahan nyeri dan masih dapat melakukan aktivitas sehari-hari seperti biasa. LBP jarang berakibat fatal, namun nyeri yang dirasakan dapat membuat penderita mengalami penurunan kemampuan dalam melakukan aktivitas seharihari, problema kesehatan kerja dan banyak kehilangan jam kerja pada usia produktif maupun usia lanjut.

Dalam penelitian yang dilakukan Atmantika (2014), ditemukan bahwa dari 180 penderita LBP akut yang diikuti selama setahun, $38 \%$ mengalami keterbatasan fungsional yang menetap. Morbiditas dapat dicegah dengan menggalakan program dari segi fisioterapi baik mengenai cara kerja yang ergonomis dan terapi yang tepat.

\section{Kelemahan Penelitian}

Beberapa kekurangan pada penelitian ini adalah: (1) Tidak ada datanya petani di Kecamatan Payangan menyebabkan digunakannya metode pengambilan data snowball sampling sehingga sampel yang didapatkan hanya yang sedang aktif dalam bekerja sehingga kemungkinan petani yang tidak aktif bekerja tidak dapat masuk ke dalam sampel. (2) Pada penelitian ini tidak dicari mengenai berapa durasi pekerja dalam melakukan posisi tersering sehingga tidak dapat dipastikan seberapa lama waktu yang dapat menyebabkan posisi tersebut dapat menyebabkan timbulnya keluhan LBP.

\section{SIMPULAN}

Adapun simpulan dari penelitian ini adalah sebagai berikut : (1) Prevalensi keluhan LBP pada petani di Wilayah Kerja UPT Kesmas Payangan sebanyak $68,6 \%$ (48 orang). (2) Berdasarkan sosiodemografi, petani yang lebih banyak mengalami LBP adalah perempuan (71\%) dibandingkan dengan laki-laki $(66,7 \%)$. Ditinjau dari segi usia, mayoritas tertinggi yang mengalami LBP adalah kelompok usia lansia (> 45 tahun) dengan persentase 73,3\%. (3) Berdasarkan faktor Risiko, bila ditinjau dari segi lama kerja diperoleh sebanyak $63,6 \%$ petani yang memiliki waktu kerja kurang dari 5 jam mengalami LBP dan sebanyak 70,6\% petani yang bekerja lebih dari sama dengan 5 jam mengalami LBP. Ditinjau dari masa kerja, sebanyak $60 \%$ petani yang bekerja kurang dari 10 tahun mengalami LBP dan sebanyak $69,2 \%$ petani yang bekerja lebih dari 10 tahun mengalami LBP. Ditinjau dari riwayat merokok, sebanyk $72,7 \%$ petani yang merokok mengalami LBP dan sebanyak 64,9\% petani yang tidak merokok mengalami LBP. Ditinjau dari posisi kerja, keluhan LBP terbanyak dikeluhkan oleh petani yang sering melakukan posisi kerja membungkuk (68,6\%). Ditinjau dari riwayat trauma, sebanyak $6,25 \%$ petani yang memiliki riwayat jatuh dan dan kecelakaan mengalami LBP. (4) Berdasarkan perilaku tatalaksana LBP pada petani, diperoleh pemijatan $(27,1 \%)$ sebagai perilaku petani tersering. Menurut dampak LBP pada kehidupan sehari-hari, sebanyak 91,7\% petani mengalami dan sebanyak $8,3 \%$ petani mengalami moderate disability.

\section{SARAN}

Adapun beberapa saran yang dapat penulis ajukan setelah melakukan penelitian ini adalah: (1) Diharapkan agar UPT Kesmas Payangan dapat memberikan penyuluhan atau pemberian informasi mengenai faktor-faktor risiko dan sosiodemografi petanu yang dapat memiliki risiko LBP agar petani dapat mencegah terjadinya keluhan LBP sehingga dapat meningkatkan taraf kesehatan petani. (2) Diharapkan pihak UPT Kesmas Payangan dapat memberikan informasi kepada para petani yang sudah memiliki keluhan LBP yang dirasa membatasi aktivitas sehari-hari agar memeriksakan keluhannya ke UPT Kesmas 
Payangan untuk mencegah terjadinya disabilitas

\section{DAFTAR PUSTAKA}

1. Andini F. (2015). Risk Factors of Low Back Pain in Workers. Journal of Majority. 4(1), halaman 11-19.

2. Atmantika NB. 2014. Hubungan antara intensitas nyeri dengan keterbatasan fungsional aktivitas sehari-hari pada penderita Low Back Pain di RSUD DR Moewardi Surakarta. Universitas Muhammadiyah Surakarta.

3. Badan Penelitian dan Pengembangan Kesehatan. Riset Kesehatan Dasar 2013. (2013). Kementrian Kesehatan RI.

4. Badan Pusat Statistik Kabupaten Gianyar. (2013). Jumlah Rumah Tangga Petani Gurem menurut Kecamatan Tahun 2003 dan 2013. Dikutip dari: http://gianyarkab.bps.go.id/2015/fronten d/linkTabelStatis/view/id/125.Akses pada 15 April 2015.

5. BN Birabi.2012. Prevalence of low back pain among peasant farmers in a rural community in South South Nigeria. University of Port Horcourt Teaching Hospital, Port Horcourt, Nigeria.

6. Borges JBC, Ferreira DLM, Silva MMA, 2006. Pain Intensity and postoperative functional assesment after heart surgery. Braz J Cardiovasc Surg

7. Bridger RS. Introduction to ergonomics international edition. Singapore: McGrawHill Book Co; 2008.

8. Deyo, 2003. Outcome measures for Low Back Pain Research. A Proposal for Standarized Use, Spine.

9. Fairbank JC, 2000. The Oswestry Disability Index, Spine.

10. Gilbovsky A, 2006, Impaired and Disabled Patients. In: Legal Medicine, American fungsional yang semakin memburuk.

College of Legal Medicine Textbook Committee, $3^{\text {rd }}$ ed. St.Louis: Mosby.

11. Gupta G.2013. prevalence of musculoskeletal disorder among farmers in Kanpur-Rural India. Journal of community and health education.

12. Gusetoiu R. (2011). Musculoskeletal Disorder in Agriculture. Jurnal of Occupational Medicine. Faculty of Mechanics University of Timisoara Romania. (29), halaman 35-46.

13. Harrianto R. Buku ajar kesehatan kerja. Jakarta: EGC; 2007.

14. Hoy D, Brooks $P$, Blyth F, Buchbinder R. The epidemiology of low back pain. Best Pract Res Clin Rheumatol 2010;24: 76981.

15. Ibrahim, 2000. Penilaian dan Pengukuran pada Nyeri Punggung Bawah Non Spesifik, MKS.

16. Kantana T. Faktor-faktor yang mempengaruhi keluhan low back pain pada kegiatan mengemudi tim ekspedisi PT. Enseval Putera Megatrading Jakarta Tahun 2010. Jakarta: Universitas Islam Negeri Syarif Hidayatullah; 2010

17. Loeser, JD. 2001. Medical Evaluation of the Patient with Pain. Dalam: Bonica's Management of Pain Part II, Lippincott Williams \& Wilkins.

18. Meliala, Asnawi. 2003, Nyeri Punggung Bawah, Dalam: Assesmen NPB, Perdossi

19. NIOSH. Musculoskeletal disorders and workplace factors: a critical review of epidemiologic evidence for work-related musculoskeletal disorders of the neck, upper extremity, and low back. NIOSH: Centers for Disease Control and Prevention; 1997.

http://intisarisainsmedis.weebly.com/ 
20. Nurwahyuni, Djajakusli R, Naiem F. Faktor yang berhubungan dengan keluhan nyeri punggung bawah pada pekerja bongkar muat barang pelabuhan nusantara kota Pare-Pare tahun 2012. Makassar: Universitas Hasanuddin; 2012.

21. Panada Taechasubamorn.2011. Prevalence of Low Back Pain among rice farmers in rural Thailand. Naresuan University Phitsanulok, Thailand.

22. PERDOSSI. (2007). Nyeri Neuropatik di Daerah Punggung Bawah (Low Back Pain): Penuntun Penatalaksanaan Nyeri Punggung Bawah. Yogyakarta: PERDOSSI.

23. Puntumetakul.2014. Prevalence and individual risk factor associated with clinical lumbal instability in rice farmers with low back pain. Journal of Dove Press.

24. Purba JS, 2006. Nyeri Punggung Bawah. Studi Epidemiologi, Patofisiologi dan Penanggulangan, BNS No. 7(2)

25. Pratiwi $M$, Setyaningsih $Y$, Kurniawan $B$, Martini. Beberapa faktor yang berpengaruh terhadap nyeri punggung bawah pada penjual jamu gendong. Jurnal Promkes 2009; 4:1.

26. Rachmawati MR., 2006. Nyeri Muskuloskeletal dan Hubungannya dengan Kemampuan Fungsional Fisik pada Lanjut Usia, Universa Medicina

27. Rakel D. (2011). Back Pain-low.Dikutip dari:

www.clinicalevidence.com/ceweb/conditi ons/msd/1102/1102 background.jsp.

Akses pada 15 April 2015

28. Robinson, JP. 2001. Evaluation of Function and Disabillity. Dalam: Bonica's Management of Pain Part II. Lippincott Williams Wilkins.
29. Setiyohadi B., 2009. Buku Ajar IImu Penyakit Dalam. Jakarta: Universitas Indonesia.

30. Silviyani V. (2014). Hubungan Posisi Bekerja Petani Lansia dengan Risiko Terjadinya Nyeri Punggung Bawah di Wilayah Kerja Puskesmas Sumberjambe Kabupaten Jember. Universitas Jember.

31. Straker LM. An overview of manual handling injury statistic in Western Australia. Perth: International Ergonomic Association Curtin University Technology; 2000.

32. Tana L, Halim FXS. Determinan nyeri pinggang pada tenaga paramedik di beberapa rumah sakit di Jakarta. J indon Med Assoc 2011; 61(4): 155-60

33. Umami AR, Hartanti RI, Dewi A. Hubungan antara karakteristik responden dan sikap kerja duduk dengan keluhan nyeri punggung bawah (low back pain) pada pekerja batik tulis. E-journal Pustaka Kesehatan 2013;2: 72-7.

34. WHO. Low back pain: Bulletin of the World Health Organization 2003; 81: 671-6.

35. Yi H. 2012. Reliability and validity of simplified chinese version of RolandMorris Questionnaire in Evaluating Rural and Urban patients with Low back Pain. Plos One. 7(1)

36. Yuliana. Low back pain. Cermin Dunia Kedokteran 2011; 38(4): 273.

37. Yunus M. (2008). Jurnal Hubungan antara Posisi Duduk dan Masa Duduk dengan Keluhan Nyeri Punggung Bawah pada Pemecah Batu Granit. Universitas Diponegoro. 